\title{
Differences in food intake and diet quality in vegans, vegetarians and omnivores in Belgium
}

Amy Mullee ${ }^{1,2}$, Laura Fiers ${ }^{3}$, Willem De Keyzer ${ }^{3}$, Tom Deliens ${ }^{4}$, Peter Clarys ${ }^{4}$, Patrick Mullie ${ }^{4}$, Peter Deriemaeker ${ }^{4}$, Barbara Vanaelst ${ }^{5}$, Rachel Wasson ${ }^{2}$, Tobias Leenaert ${ }^{6}$, Stefaan De Henauw ${ }^{5}$, Marc J. Gunter², Inge Huybrechts ${ }^{2,4}$

${ }^{1}$ School of Public Health, Physiotherapy and Population Science, University College Dublin (UCD), Dublin, Republic of Ireland, ${ }^{2}$ International Agency for Research on Cancer (IARC), Lyon, France, ${ }^{3}$ University College Ghent, Department of Bio- and Food Sciences, Ghent, Belgium, ${ }^{4}$ Faculty of Physical Education and Physiotherapy, Department Movement and Sport Sciences, Vrije Universiteit Brussel, Brussels, Belgium, ${ }^{5}$ Ghent University, Department of Public Health, UZ-Ghent, Ghent, Belgium, ${ }^{6}$ EVA vzw, Ghent, Belgium

\section{Introduction}

- There is a risk that when animal products are insufficiently substituted by nutritious plant-based foods, a vegetarian or vegan diet could possibly lead to inadequacies for certain nutrients.

- Little is known about the quality of the diet of Belgian vegans and (semi-)vegetarians in comparison with Belgian omnivores and their compliance with the food based dietary guidelines (FBDG).

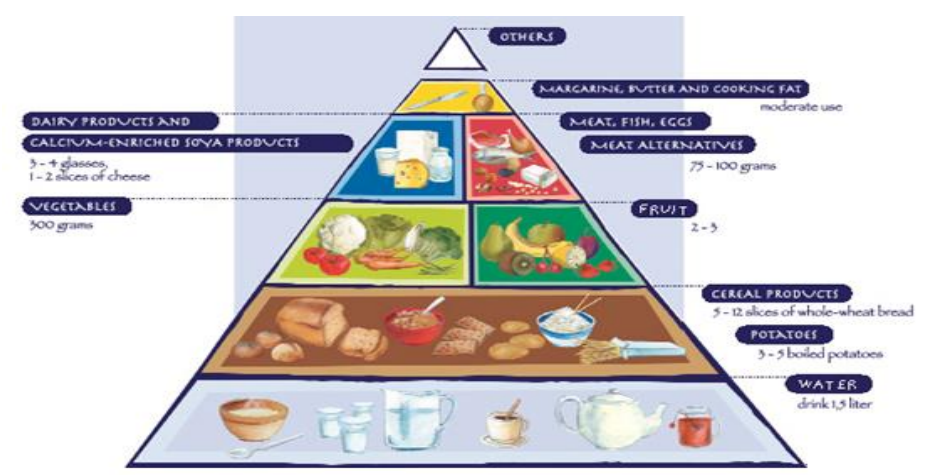

Figure 1. Belgian Food Based Dietary Guidelines Pyramid adapted from Vigez ${ }^{(1)}$

\section{Aim}

To examine the diet quality of vegans, vegetarians, semi-vegetarians and omnivores using a diet quality index (DQI) especially developed alongside the Belgian FBDG.

\section{Methods}

Males and females aged $14-83$ years; $\mathrm{n}=3,039$ from the 2004 Belgian food consumption survey ${ }^{(2)}$ and $n=1,803$ recruited through a Belgian vegetarian organization and Universities in Ghent completed an online questionnaire including a selfreported food frequency questionnaire.

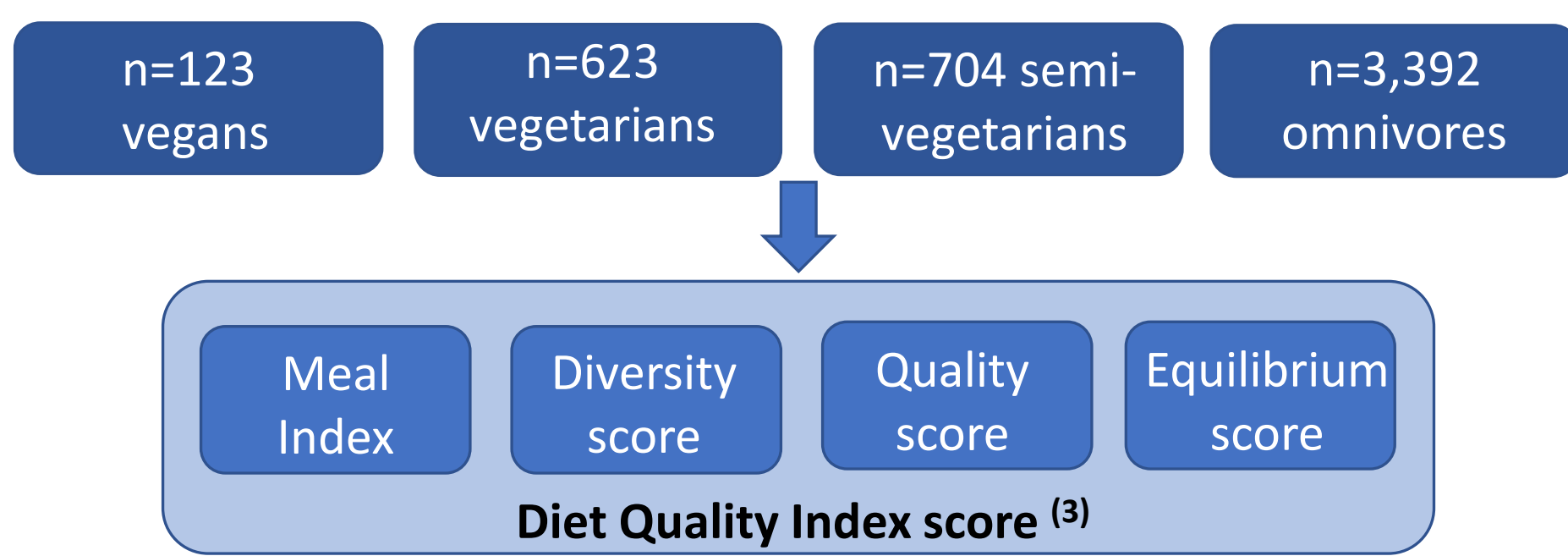

\section{Results}

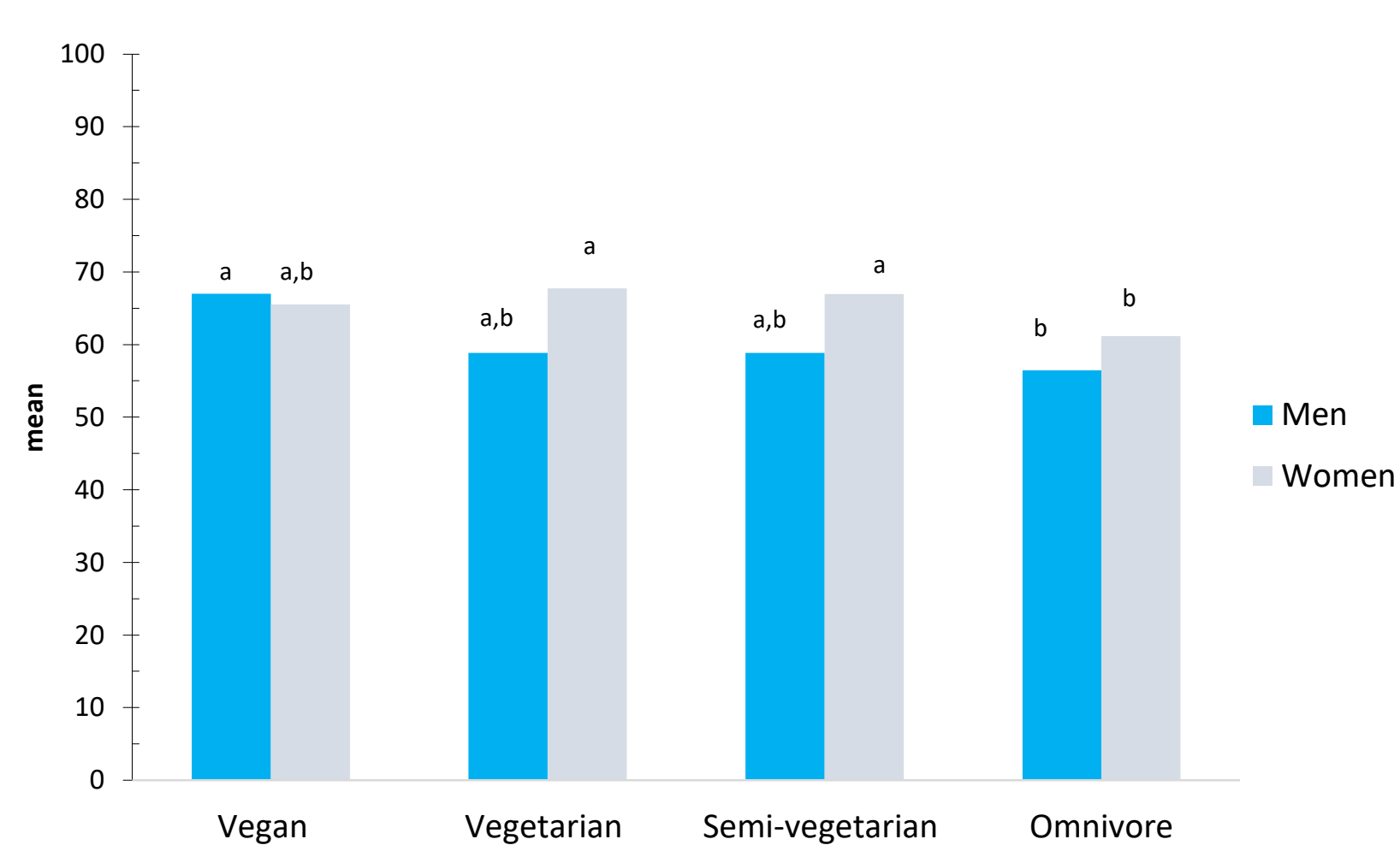

Figure 3. Mean diet quality index (DQI) score for male and females. Different superscripts indicate statistical difference between dietary patterns in men and women, respectively $(p<0.05)$
- None of the dietary pattern groups were fully compliant with the FBDG.

- All dietary pattern groups did meet the minimum recommendation for protein sources.

- Recommendations for dairy or calciumfortified drinks were not met in any of the dietary pattern groups, although vegans, vegetarians, and semi-vegetarians consumed at least 1.7 times more milk or soya drinks than omnivores.

\section{Conclusion}

Vegans, vegetarians and semi-vegetarians appear to adequately compensate for the absence or reduced intake of animal protein, and conform to the FBDG as much as, or better than omnivores. However, none of the dietary patterns complied with all the Belgian dietary recommendations.

\section{References}

1. Vigez (2012) The Active Food Guide Pyramid. Belgium: Het Vlaams Instituut voor Gezondheidspromotie en Ziektepreventie (VIGeZ)

2. De Vriese S, Huybrechts I, Moreau M et al. (2006). The Belgian Food Consumption Survey 1 - 2004: Report (Enquête de consommation alimentaire Belge 1 - 2004 Rapport). Report No.: D/2006/2505/16. Brussel: Afdeling Epidemiologie

3. Huybrechts I, Vereecken C, De Bacquer D et al. (2010) Br J Nutr 104, 135-44.

\section{Acknowledgements}

The work that Amy Mullee contributed to in this abstract was undertaken during the tenure of an IARC-Ireland Postdoctoral Fellowship from the International Agency for Research on Cancer, funded by the Irish Cancer Society. 